\title{
A SIMULATION STUDY FOR THE SUSTAINABILITY AND REDUCTION OF WASTE IN WAREHOUSE LOGISTICS
}

\author{
Burinskiene, A. ; Lorenc, A. ${ }^{* *} \&$ Lerher, T. $^{* * *}$ \\ *Vilnius Gediminas Technical University, Department of International Economics and Management, \\ Saulètekio al. 11, Vilnius 10221, Lithuania \\ ${ }^{* * *}$ Cracow University of Technology, Faculty of Mechanical Engineering, al. Jana Pawła II 37, \\ 31-864 Cracow, Poland \\ **** University of Maribor, Faculty of Logistics, Mariborska 7, 3000 Celje, Slovenia \\ E-Mail: aurelija.burinskiene@vgtu.lt, alorenc@pk.edu.pl, tone.lerher@um.si
}

\begin{abstract}
In this study, the authors have investigated warehouse processes to identify critical ones that are wasteful. The aim of this research study was to improve the efficiency of warehouse processes by reducing travel time and cost in replenishment and order picking. To achieve this objective, the authors have proposed a mathematical model and discrete event simulation study. For the simulation model, the Dijkstra algorithm has been selected to schedule forklifts driving and picking vehicles routes in internal transport. According to the extensive simulation analysis approximately $67 \%$ of waste could be reduced in warehouses. Of course, this number depends significantly on a warehouse layout, operations and material handling equipment used in warehouses.

(Received in March 2018, accepted in June 2018. This paper was with the authors 2 weeks for 1 revision.)
\end{abstract}

Key Words: Logistics, Warehousing, Discrete Event Simulation, Sustainability, Performance Analysis

\section{INTRODUCTION}

The need to integrate environmental, social and economic aspects into the logistics has created a debate among researchers on sustainability in logistics. The concept of sustainability does not cover just ordinal enterprise activity only. It includes management of logistics system along with managing economies of resources and transaction costs and securing population ecology and environment. There is an endless search for better performance in logistics avoiding over-costs by improving warehouses and transportation processes by using more fuel-efficient transportation technologies, i.e., in general, working out solutions that brings costs reduction, safety to the environment and improvement in competitiveness.

The object of this research study is an efficient use of warehouse resources. The authors of this article have revised many studies on sustainability in logistics to investigate the newest trends and provide valuable insights on the topic. The study has its limitation as focus area is narrowed to warehouse in empirical part. Nevertheless, the results are very valuable for experts interested in waste reduction and logistics efficiency improvement. The originality of the research is the application of the Dijkstra algorithm for waste for main warehouse processes calculation. It is the illustration of possible application of simulation modelling for logistics processes improvements, based on minimization of total travel distance of machinery doing different warehousing tasks, which are generated in a referenced warehouse based on waste pyramid.

\section{LITERATURE REVIEW ON SIMULATION AND SUSTAINABILITY}

The research on sustainability in logistics is quite actual with the aim to achieve better performance. There are many simulation models used and developed for sustainable logistics studies: system dynamics (for qualitative insights), discrete event dynamic system simulation 
(for the corporation of uncertainties), and business games (for education). In these studies, authors give specific attention to transport system dynamics.

$\mathrm{Li}$ and Yeh [1] have focused in their research on sustainability in urban areas and suggested simulation model to measure distances to logistics infrastructure. Zachariadis [2] designed simulation model capable for tracking sustainability opportunities in transportation. Knaak et al. [3] delivered optimisation-based simulation model, which shows significant economic and ecological improvements in courier services. They came to conclusion that orders, which destination point is near pick-up, have to be delivered directly to avoid unnecessary movements and delay of orders. Pawlewski and Greenwood [4] delivered series of numerous studies. Most of these studies were dedicated to transportation and its impact on logistics. Checinski [5] presented simulation analysis on freight transport congestion. Jacyna et al. [6] simulated the minimization of transportation time, trip distance and related costs. Carteni [7] provided simulation with rational decisions in transportation planning. Petranovic et al. [8] developed models dedicated to achieving sustainable transport sector. There have emerged much more papers in logistics with primary focus to sustainable transportation. Such studies were very popular, because transportation sector is responsible for 20-40\% of $\mathrm{CO}_{2}$ emission.

Simulation is a useful tool in estimation of savings and other benefits gained from the reduction of congestion, $\mathrm{CO}_{2}$ emission, travel time, and traffic accidents. Apparently, urban areas are in need to reduce the consumption of resources by applying these suggestions. In warehouse similar processes occur like in the city, but in smaller scale.

Apart from transportation, there are not many studies in other logistics suitability. GarcíaArca et al. [9] delivered study for selecting sustainable packing, which is important for logistics operations. Tan et al. [10] modelled sustainability in warehouse and providing various sustainability models covering simulation applied for distribution company type.

The above presented research papers support the application of discrete event simulation of warehouse processes to gain sustainability, which will be applied in our paper.

\section{SUSTAINABLE WAREHOUSE ACTIVITIES}

The move towards sustainable society requires greater attention to waste management. As logistics consume energy resources, companies follow practices to lower energy consumption and waste production [11]. Logistics should demonstrate a strong commitment to protect environment and operate in the way, which supports the use of the Earth resources wisely [12].

As many logistics studies are dedicated to transportation, its impact on logistics and the reduction of carbon emission, the authors of this paper have decided to investigate a warehouse and reduce this emission by shorten the forklifts travel distance. A warehouse system has links to other parts of logistics and potential of increasing its contribution. In the next section, warehouse operations aiming to produce more sustainable practices, will be presented. These practices will be examined through the discrete event simulation and will give guidelines how to make warehouse operations more sustainable [13-16].

In a warehouse, products are received in pallets, afterwards they are placed (put-away) to storage and then replenished from a storage to a picking area in accordance to customers' orders [17]. Therefore, the material flow is based on the following activities: receiving, putaway to storage, replenishment from storage and picking for shipping full pallets according to the customers' orders (Fig. 2). The objective of the case study is to simulate waste reduction for the above-mentioned warehouse operations. The waste also depends on the location of the receiving and dispatch area, storage policy and order picking policy, which are presented in Fig. 1. 

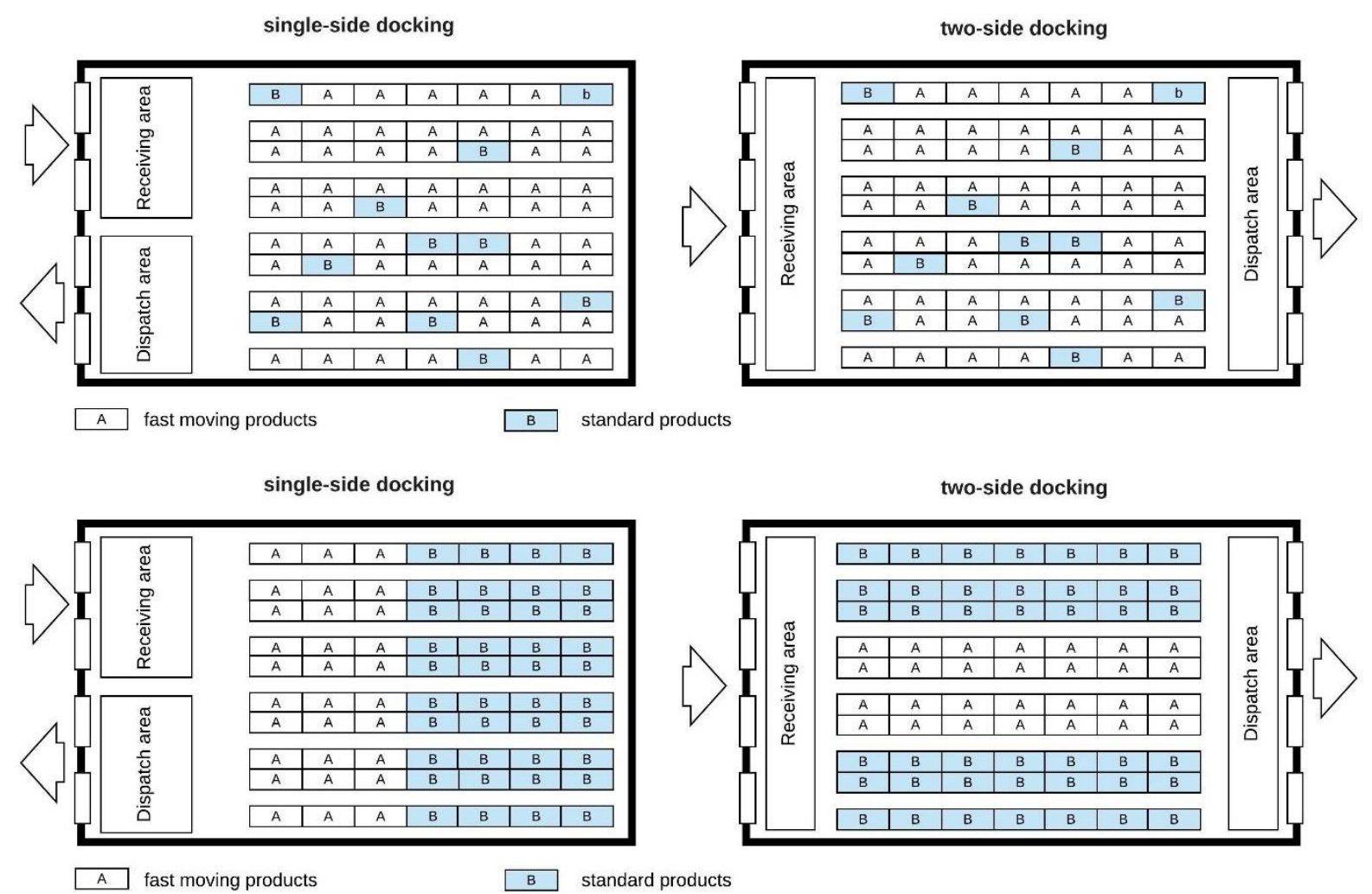

Figure 1: Different storage policies in single-side docking and two-side docking.

In the case study, authors analysed waste in warehouse process that is generated by handling material units from one function to another in a sequenced way [18]. As the costs of each activity differs, receiving is specified as an activity having the lowest costs and picking of customers' orders activity is treated as having the highest costs (see waste generation pyramid).

To identify the size of waste in a warehouse the authors created waste generation pyramid. In each layer of the pyramid, different resources are wasted:

- Forklifts are used for such activities as receiving, put-away to storage, picking full pallets (customers' pallets) and replenishing from the storage to the picking area. They (i.e. counter balance trucks) are relatively high energy consuming machinery due to possibility to handle several types of activities. The development of the least-costs routes can help to remove waste. In warehouses, forklifts are the main machinery that consumes electricity. The main wastes in applying forklifts are as follows: empty driving, acceleration and deceleration, fork platform manipulations and turning of the machinery [19].

- Order picking vehicles participate in picking-intensive processes (case picking), which consume app. $65 \%$ of the operations costs. The picking activity may include machinery, which is used by each order picker to handle customers' orders in a warehouse. In any case, machinery consumes energy and has the costs of electricity to power vehicles. Any improvement in travelling of order picking vehicles brings waste reduction as can be judged of the scale of resources savings. In picking process, the waste of time is related with: using terminals, scanning, searching for products, carrying products, cutting carton and time waste for getting off and in by driver [20,21].

In continuation, the theoretical framework for waste avoidance is presented. In sequence, receiving process requires around 10 percent of operational costs [22], specifies requirements how goods arrive to operation place [23] and includes inbound of the goods. The order placed to supplier consists of a mix of products. The arrival schedule specifies which products must arrive first and which of them afterwards. Many of high-volume products have more 
than five pallets in inventory [24]. Put-away is a next process in a row, which is initiated when storage location is known. This is very important because Warehouse Management System (WMS) must monitor in real-time which storage locations are available, and which locations are dedicated for specific type of goods and where each pallet of the goods is stored [22].

According to Karasek [22], the storage locations are often selected randomly. Such selection could be organized by using rule by which where goods should be clustered according to the customers' orders frequency. It suggests that the most frequently requested goods should be the ones closest to receiving / shipping gates.

After customers' orders are entered, replenishment is generated from reserve to a forward storage area where order pickers begin case picking. In addition, the forklifts start picking customers' pallets directly from storage (i.e. a reserve area). These actions continue until picking of cases and pallets are completed and an order is shipped to a customer.
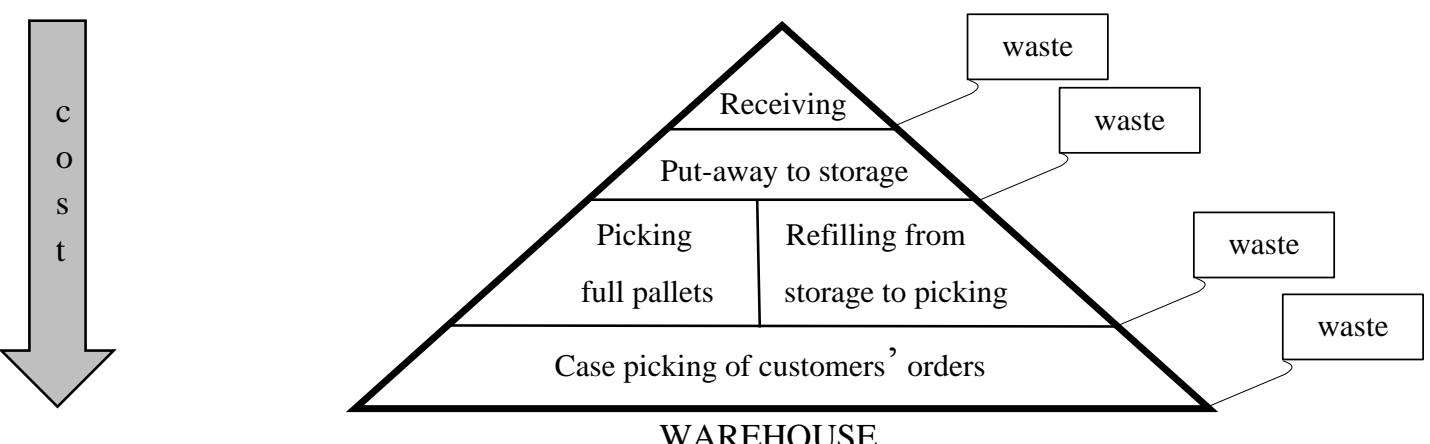

Figure 2: Waste generation pyramid.

Waste for each activity was identified through simulation. The simulation instrument allowed the comparison of different scenarios. Well-known travel-simulation instruments are capable to separate efficient and non-efficient use of resources which behaviour is analysed later [25]. It is well known that to perform warehouse operations proper scenario must be selected. In many cases, forklifts and orders pickers are travelling unnecessary distance. During the analysis, the authors [17] found out that warehouse resources contributed to output only one third of the time as another time they were just busy with unnecessary movements.

\section{THE SIMULATION FRAMEWORK}

In the process of designing the theoretical framework, we employed the approach of integrated sustainable warehouse activities with various opportunities of utilisation of the resources. The main target of this framework is the focus on the inner transportation as the main source of the waste generation in a warehouse provided it is not well constructed. Therefore, an optimization of the inner transportation must lead to the significant decrease of waste in a warehouse.

\subsection{Receiving and put-away to storage}

After being received into a warehouse, the products (pallets) to be transported to their storage locations. As they are stored in different aisles, the routing depends on locations where products are received and where they are stored. In Fig. 2, there is a presentation of the route. The first option shows a case when a product is received straight in front of a storage aisle (A). The second option shows a situation when the route of product transportation is longer (B). 
For high volume products, there is important to have storage location as much as closer to picking location (which, in most cases, is one per product type). Therefore, in Fig. 2 b, we see distances $D_{\mathrm{r} 1}$ and $D_{\mathrm{r} 2}$ between the storage (reserve) area $R_{0}$ and the locations $R_{1}, R_{2}$ in picking area. A forklift truck must replenish picking $\left(R_{1}, R_{2}\right.$, etc.) locations where an order-picker takes products from the storage location $R_{0}$. Because of it, a distance between the locations is important.
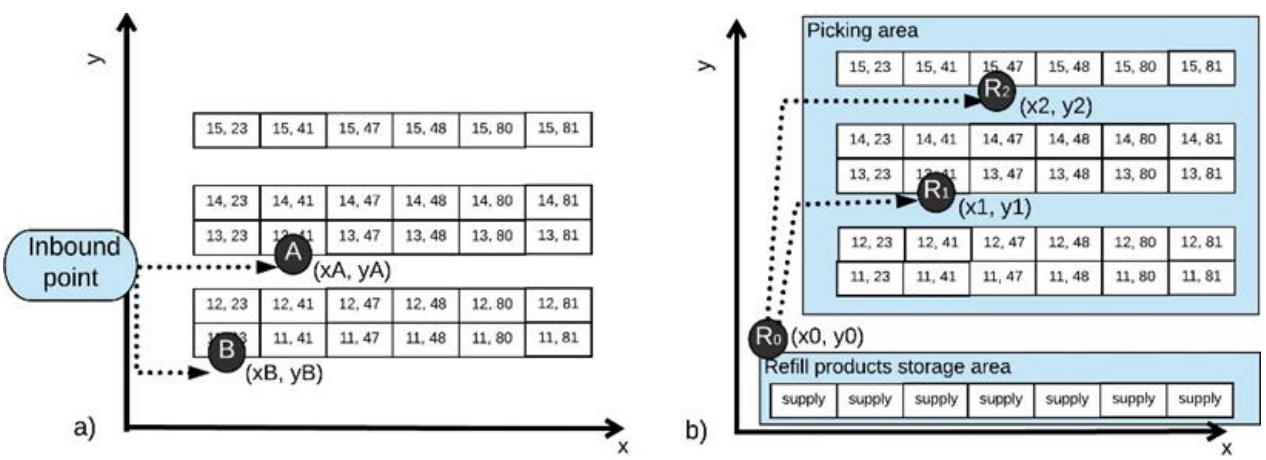

Figure 3: a) Receiving lines location and inner transportation trajectory to A and B aisles; b) Distance between picking and storage locations which are selected during put-away to storage activity.

In our case study, a selected warehouse contains 47 aisles and in each of them there are 131 storage locations. In total, there are 18.471 coordinates involved in shortest trip distance calculation in the warehouse. Width of the storage aisle equals 3.5 meters, width of the storage location equals 0.85 meters, length of the storage location equals 1.25 meters and height of the storage location equals 1.8 meter. In Fig. 4 part of the picture with 20 locations is presented, where vertexes and nodes and numbered (vertexes are identified with small letter in front).

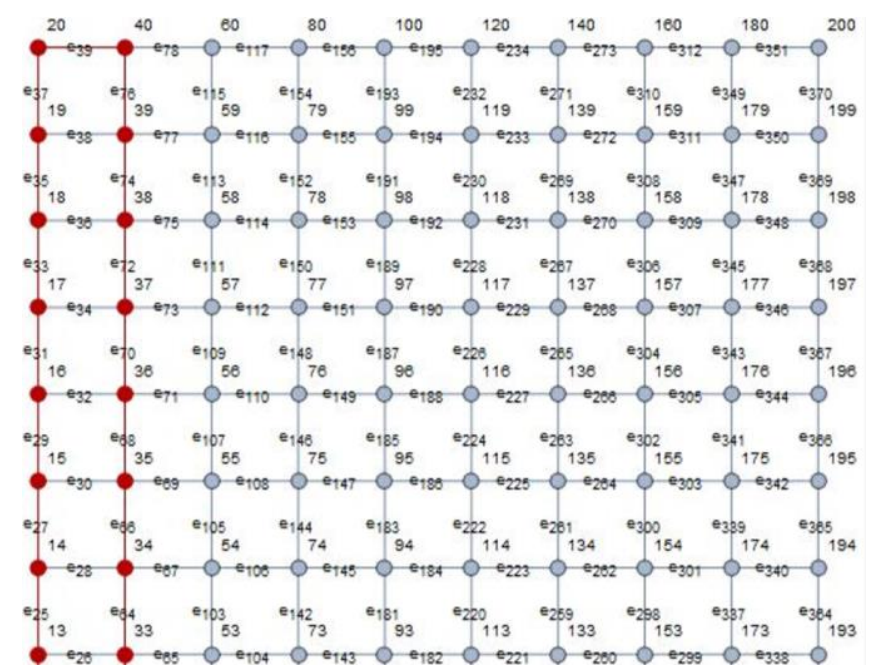

Figure 4: The warehouse structure presented as an inner-transport network that includes locations of products (nodes) and vertexes.

\subsection{Picking and replenishment}

In the warehouse that served as our data source, $25 \%$ of the products were picked as full customers' pallets. Therefore, all forklifts (counter balance trucks) could perform:

- separate tasks: pick full pallets, replenish products from storage area to picking area, transfer from receiving area to storage area;

- combined tasks: pick full pallets, replenish products from storage area to picking area, transfer from receiving area to storage area. 
The forklifts perform combined tasks that can take one or two pallets in the same time. While forklifts carry out separate tasks, they can travel around empty app. 50 percent of a total distance. Having all single activities combined during the cycle, the length of the travel distance of forklifts is too high and ineffective and therefore should be reduced. This type of machinery (i.e. counter balance trucks) needs the aisle width 3.5 meters. In the simulation model, the mean forklifts velocity was set to $v_{x}=1.39 \mathrm{~m} / \mathrm{s}$. The minimum velocity on a straight section was set to $v_{x}=0.97 \mathrm{~m} / \mathrm{s}$, and the maximum velocity was set to $v_{x}=1.81 \mathrm{~m} / \mathrm{s}$. The standard deviation was 0.246 . Furthermore, actions as acceleration and braking times, or slowing down at turns were included as penalties in our simulation model. Some assigned tasks have weight which prioritises the task by placing higher priority $C p$. These tasks have less possibility to be inserted into combined tasks approach overviewed bellow.

\subsection{Case picking of customer's orders}

Cases with products inside are picked in accordance with the pick by order policy. Because the products are in different aisles, in most cases, a considerable travelling distance between product locations appears usually. In addition, there might be many by-passed products. To reduce the travelling distance, several customers' orders must be picked at once. If the product is included to the same picking route (i.e. multi-picking is constructed), it effects travelling distance positively.

In the simulation model, an order algorithm sorts out products listed in different orders to increase effectiveness of the picking process. Therefore, in the simulation model, the mixed picking policy has been taken (pick by order and pick by location). For route planning, a distance minimisation algorithm has been used.

The order picking operation employs order picking vehicles. Each order picker's carrier moves from one point to another according to the assigned tasks and finally it returns to its original location, i.e. charging room. Each assigned task is executed only once.

\subsection{The model}

There are five types of tasks in the wide-aisle warehouse as presented above in the waste generation pyramid. To perform these tasks, we have selected two types of transport mode: forklifts and order picking vehicles. The forklifts move customers' pallets, while the order picking carriers collect customer orders. If the transport mode $(r)$ is located at the point $(s)$; when it moves to point $(t)$ it spends energy, which depends on the length of the travelling distance. Moving vehicle requires energy $(c)$, which is expressed in a distance unit. The objective is to find the minimal distance, which reduces total energy $(E)$ for executing the number of tasks $(j)$ in warehouse.

For simulation, the Dijkstra algorithm has been selected from among other shortest-path algorithms. Beker et al. [18] compared the options and implemented the Dijkstra for guiding forklifts in warehouse. Therefore, a route selection is not the object of this study - it focuses more on how to figure out the best combination of inner-transportation.

Total energy $E$ for 5 tasks $(j)$ is calculated by the Eq. (1):

$$
E=\sum_{j=1}^{5} \sum_{i=1}^{n} T_{j} c_{i}
$$

The shortest distance $T$ is calculated by the Eq. (2):

$$
T=\operatorname{Min}\left(D_{r_{1}}^{s t}, D_{r_{2}}^{s t}, \ldots, D_{r_{n}}^{s t}\right)
$$

For next step the position of the forklift between points is checked. If the forklift stays in the same aisle the $A_{p}$ is 0 , otherwise $A_{p}$ is 1 . Where distance $D^{s t}$ for the forklift is calculated by the Eq. (3): 


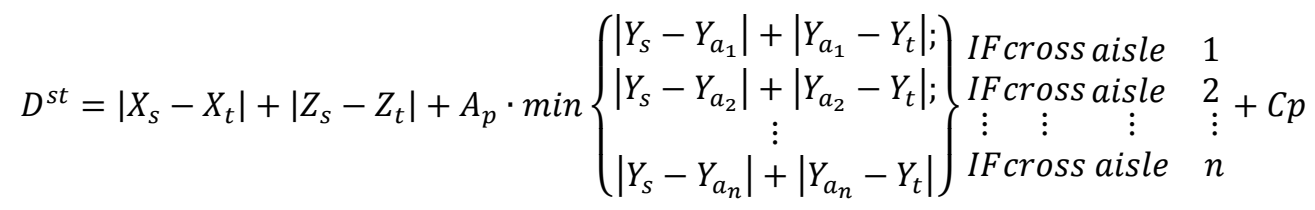

where distance $D^{s t}$ for the order-picking vehicle is calculated by the Eq. (4):

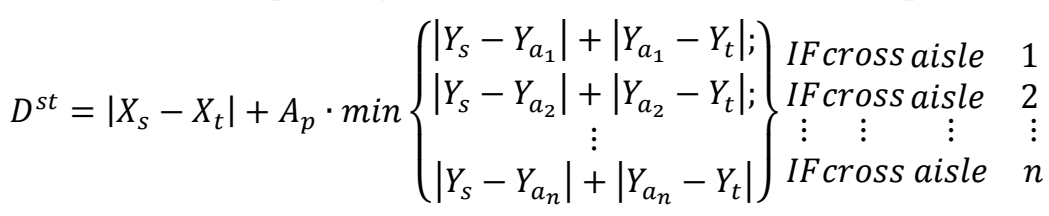

Notations:

$\begin{array}{llll}C p & \text { - Index for priority } & X, Y, Z & \text { - Coordinates of machinery } \\ r_{1,2, \ldots, n} & \text { - Warehouse machinery } & X_{S ; t}, Y_{S ; t,} Z_{S ; t} & \text { - Coordinates of locations } \\ D^{s t} & \text { - Distance between two successive } & X_{a 1, a 2, \ldots, a n ;} & \text { - Coordinates of cross-aisles } \\ & \text { task locations }(s, t \text { locations) } & Y_{a 1, a 2, \ldots, a n} & \end{array}$

Each point is defined in the Euclidean dimensional space with $\mathrm{X}, \mathrm{Y}$ and $\mathrm{Z}$ coordinates.

\section{THE SIMULATION ANALYSIS}

Aiming to analyse inner transportation waste in the warehouse, the authors created the simulation model with a Wolfram Matematica package, while statistical data was processed with EViewer statistical package.

For simulation of inner transport processes, the simulation model employs the Dijkstra algorithm heavily, that allows figuring out the shortest route between selected nodes of the reference warehouse. Generally, this algorithm consists of four steps: (1) a generation of all possible routes for moving from point $s$ to point $t(\mathrm{P} 2 \mathrm{P})$. It doesn't allow moving back and examines 2-4 nodes upfront in search for an optimal route; (2) each route contains: (a) allocation of intermediate points - vertexes; (b) length calculation of connected edges in a route; (c) distance calculation from $s$ to $t$ (sum of all edges in a rout); (3) an application of minimisation function along all calculated routes; (4) this cycle is repeatable for each task.

There are two matrices which duplicate each other: one is a matrix of vertexes (designated as $a$ ) and other is a matrix of locations which are coordinates ( $x$ and $y$ are in meters) of locations in the warehouse. For example, the location $l_{11}$ has coordinates of $[0,0]$.

$$
\left[\begin{array}{cccc}
a_{m} & a_{m+m} & \cdots & a_{k m+m} \\
\vdots & \ddots & \therefore & \vdots \\
a_{2} & a_{m+2} & \ddots & a_{k m+2} \\
a_{1} & a_{m+1} & \cdots & a_{k m+1}
\end{array}\right] \Leftrightarrow\left[\begin{array}{cccc}
l_{m 1} & l_{m 2} & \cdots & l_{m k} \\
\vdots & \dot{\ddots} & \ddots & \vdots \\
l_{21} & l_{22} & \ddots & l_{2 k} \\
l_{11} & l_{12} & \cdots & l_{1 k}
\end{array}\right]
$$

where aisles $j \in(1, k)$; depth of aisle $i \in(1, m)$.

In the simulation, different scenarios were compared. The authors entered 1000 tasks that may sorted out as follows: 324 tasks of them were for receiving, 324 - for put-away (transfer from receiving area to storage area), 78 - for picking full customers' pallets ( 28 - with high priority index and 50 - without priority index), 139 - for replenishment products from storage area to picking area, and 135- for picking cases. Finally, 50 combined tasks, that were constructed from four activities, were designed for forklifts, including operations in full cycle: receiving (1), put-away from receiving area to storage area (2), picking full pallets from storage area and to dispatch area (3), replenishing from storage area to picking area (4). In addition, a scenario of grouping multiple customers' orders was investigated in a search for the most efficient way of carrying out order picking process (5).

A set of experiments was performed with real data. In the simulation analysis, we tested different strategies and compared their outcomes with the fundamental strategy. The discrete event simulation was used to analyse different improvement options for each activity. The 
simulation deals with real processes, which occur in the warehouse. Many resources were employed in the reference warehouse. The study is limited to one block manual handling single-side docking warehouse. The developed simulation model is used to estimate total travelling distance for machinery movements during one day period. Therefore, the summarised travel distance was used as a benchmark for testing different scenarios.

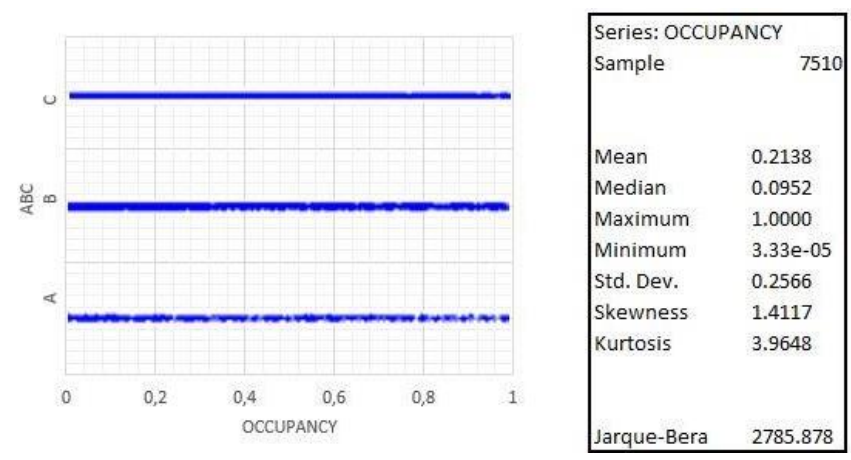

Figure 5: Statistics of picking locations before picking.

The results of the simulation study demonstrate that the construction of combined tasks helps minimise unnecessary movement and avoids waste in the warehouse (in a sequence way):

1) In the reference warehouse, fast moving products were not inbounded in front of their storage area. The authors tested different strategies and identified $t$ options to receive fast moving (high-volume) products as closer as possible to storage area, which gives economy of total distance up to $7.5 \%$. The simulation showed that there is a need to re-design inbound processes to improve warehouse operations. There are many suppliers all day delivering products to the warehouse. Sometimes suppliers deliver low-volume products before fast moving products come in, therefore last ones get locations far away from the doors. Considering this fact, the major revision of supplier's delivery plan is required;

2) In reference warehouse, storage places of high volume products were far away from picking places because of space shortage. To reach distance economy storage locations for high volume products must be upfront prioritized as closer as possible to picking locations. Such shall shorten total distance up to $7.2 \%$.

The simulation results showed that high volume products must be prioritised in warehouse operations. To implement it, products have to be separated into fast moving and standard products, which later on have to be used for identification and prioritisation of particular ones during daily operations. For the implementation of this solution, an arrival and dispatch plan of products in warehouse could be useful;

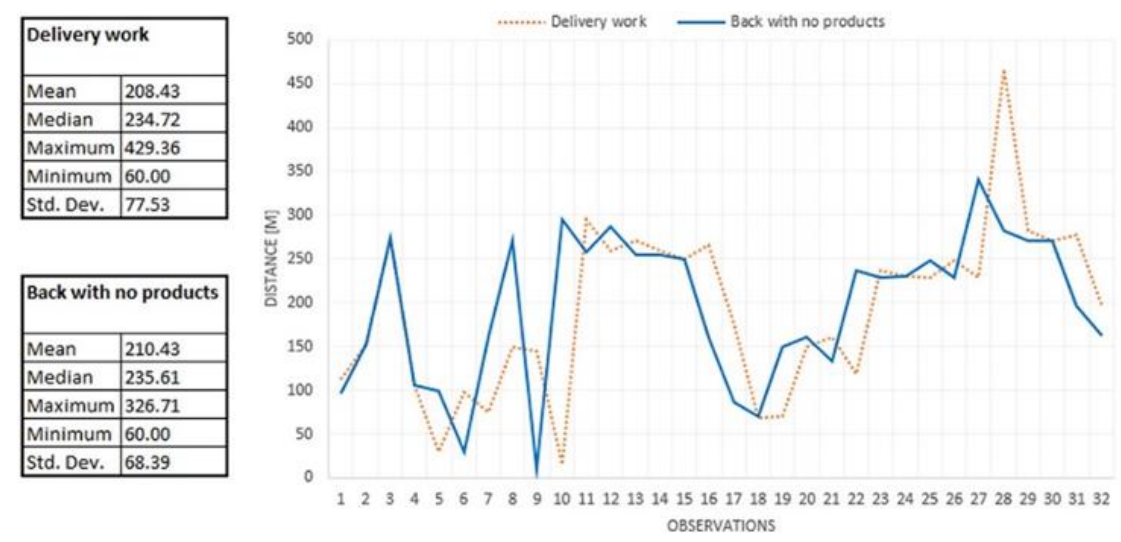

Figure 6: Inner transportation to storage. In sequence way: first - receiving lines are randomly chosen, second - receiving lines for A products are selected (the way with no products presents waste). 


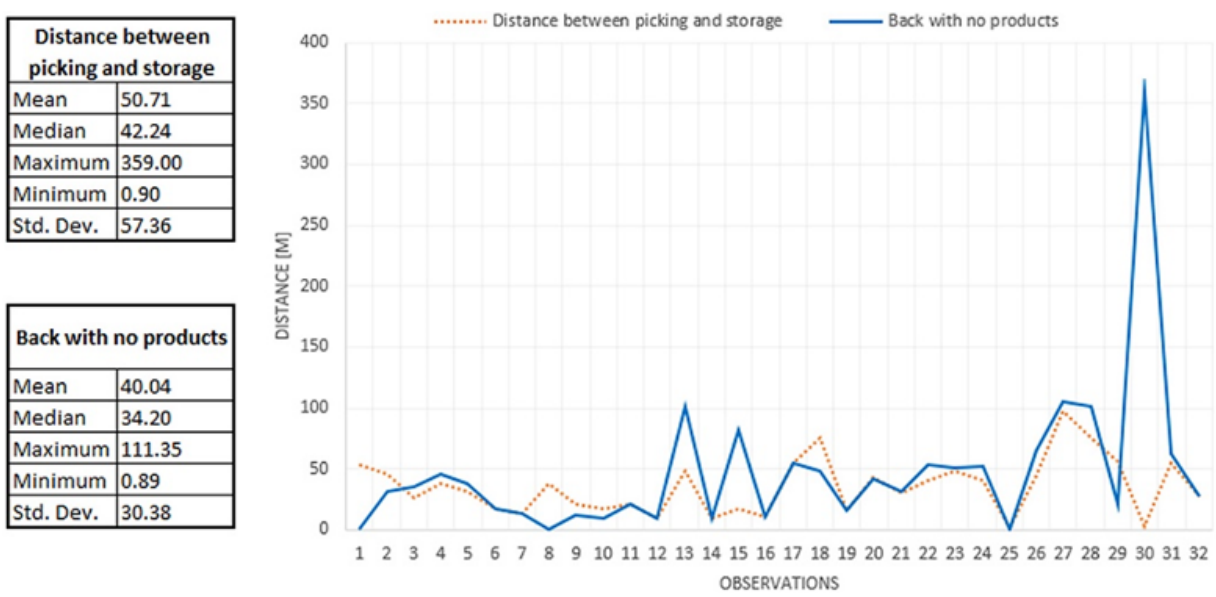

Figure 7: Inner transportation between picking and storage locations. In sequence way: first - storage locations are randomly chosen, second - storage locations for A products are selected.

3) In reference warehouse, there was $24 \%$ of total volume that was picked in full pallets. The authors revised the case and found an evidence that $50 \%$ of its distance the forklifts went empty. The optional solution was based on combined tasks that allowed for reaching economy of total distance up to $40.7 \%$. The simulation tests confirmed that the routing of forklift must be revised to increase the number of combined routes. This process was repeated until all tasks were grouped, and consequently - the routes were created. Afterwards, a choice must be made by warehouse management system before directing a forklift to a route. It is worth mentioning, that a number of locations per order is 64.5. The correlation between customers' orders (x) and order lines (y) could be described by Eq. (6):

$$
y=-1.3487 x+88.763
$$

4) In the reference warehouse, replenishment was requested by the order pickers. The authors identified that the delivery of replenishment tasks upfront picking shortens the total distance of the order pickers by $50.3 \%$.
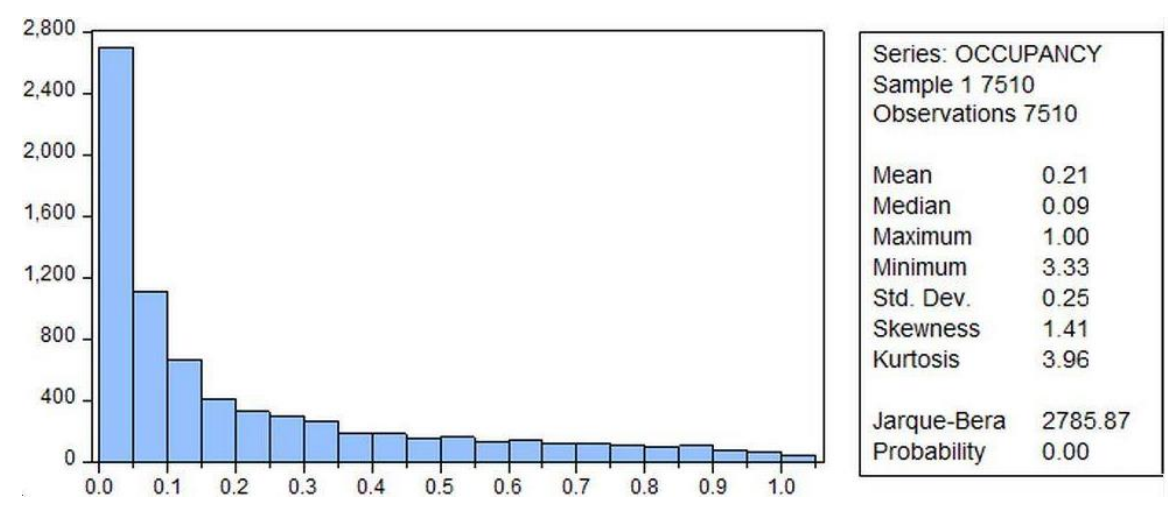

Figure 8: Digital engineering for productivity improvement.

Aiming to reduce extra travelling of the pickers during the picking period, there is a need to implement a refilling improvement strategy. Once per hour, a forklift comes to the aisle and does all refilling tasks. The generation of refilling tasks is constantly required in the warehouse management system;

5) In the reference warehouse, the order pickers pick orders of different customers' separately. The results of simulation brought an evidence that multi-picking was beneficial. The picking of multiple orders at the same time brought economy of total distance up to $21.8 \%$ or even higher. The simulation results showed that multi-picking outperforms the 
single customer order picking strategy. To deliver multi-picking, some changes must be made in the warehouse management system. In addition, the logic of 'pick-and-sort' at each location for an order picker must be implemented. For multi-picking, special double pallets order picking vehicles must be used. For picking individual products a multipicking cart must be used to separate clients' orders. An extra cart for multi-picking does not cause significant energy consumption. In the presented simulation, the used vehicles have similar energy consumption level. Therefore, they were not compared. The second reason why such kind of comparison is absent in the research is that the main aim of the research was to identify the waste related with distance covered.
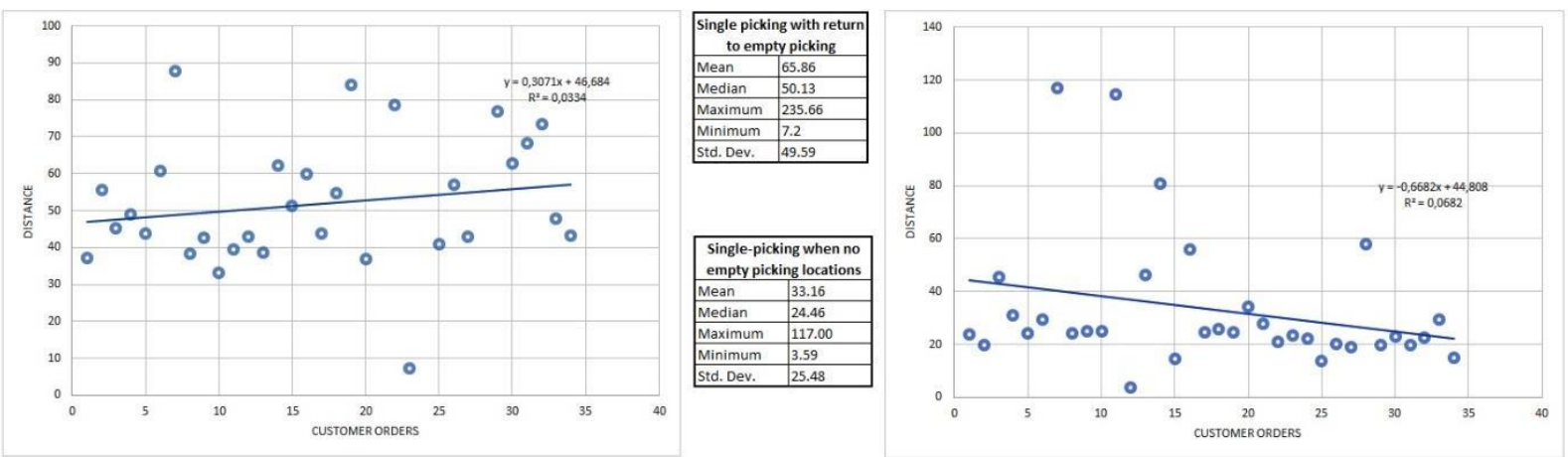

Figure 9: Inner transportation of picking orders: On the left - single picking with return to empty picking locations, on the right - single-picking when no empty picking locations.
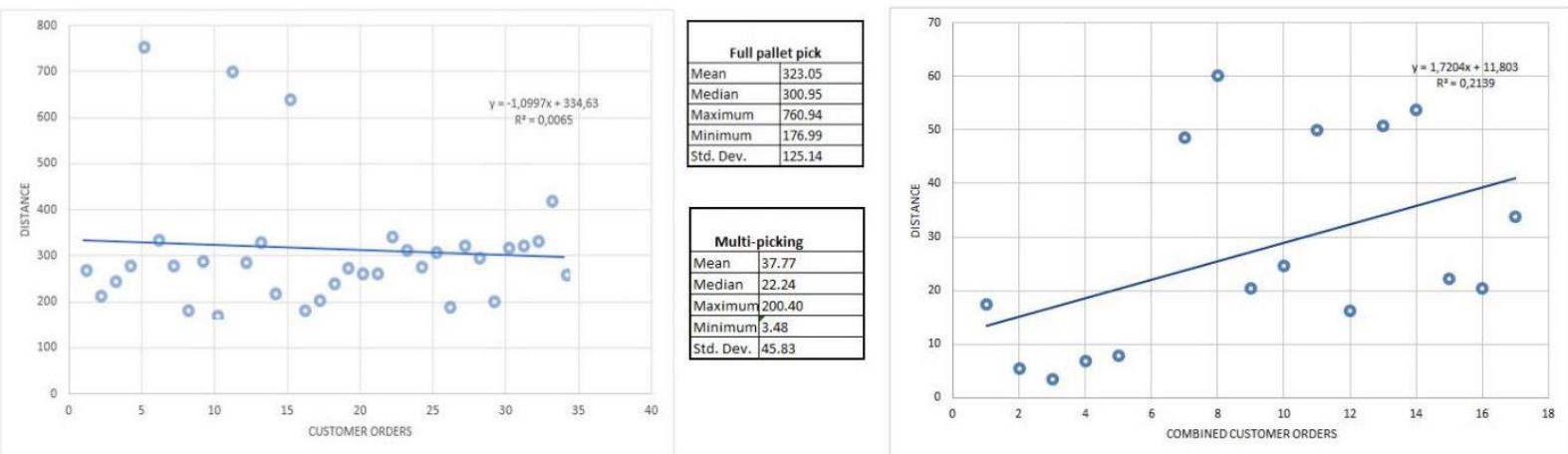

Figure 10: Inner transportation of picking orders; picking full pallets (left), multi-picking (right).

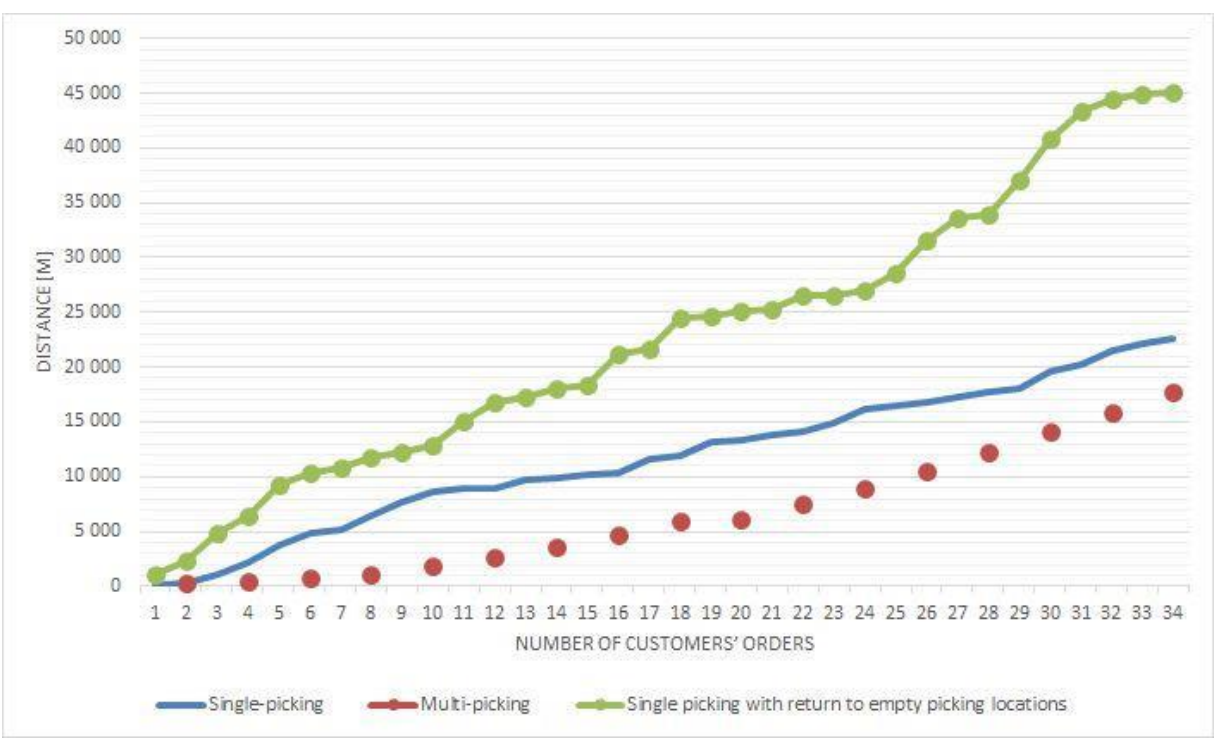

Figure 11: Total distance for the picking scenarios - accumulated waste reduction. 


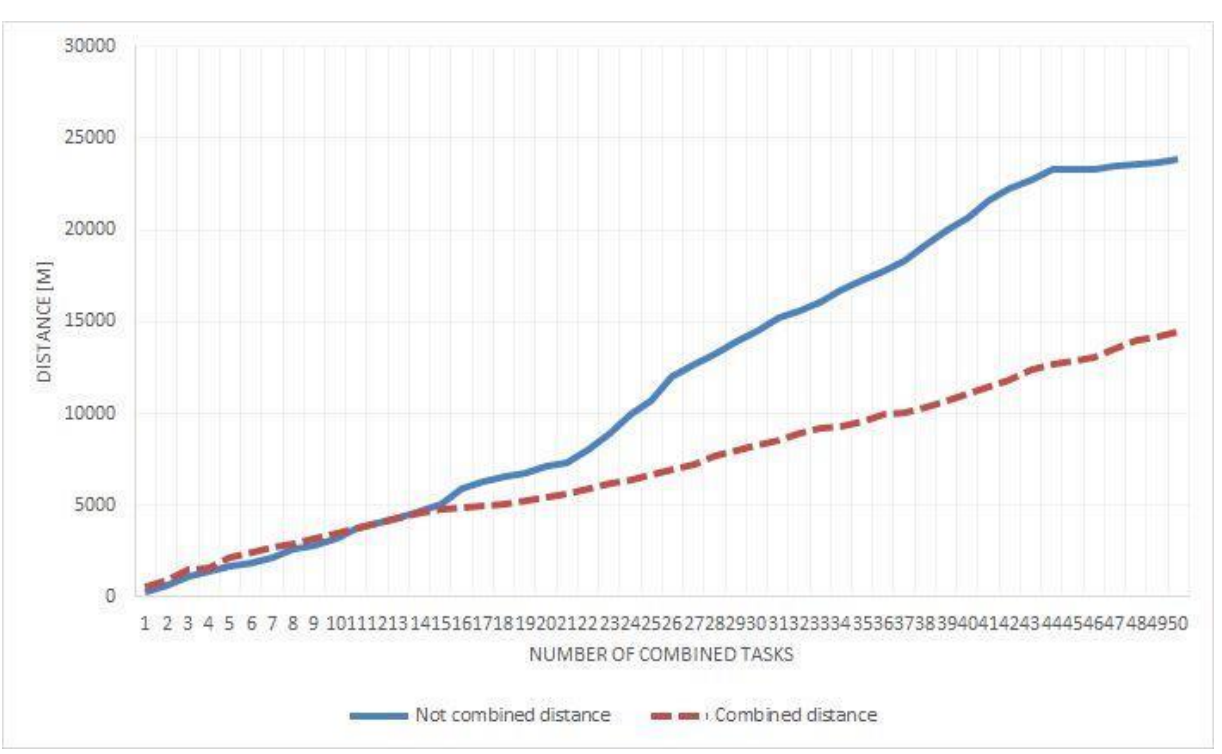

Figure 12: Total distance for the combined tasks scenarios - accumulated waste reduction.

The simulation results reveal significant improvement: in total both solutions bring $40.7 \%$ of reduction in forklifts total travel distance and economy of order picking vehicles' total trip distance up to $60.7 \%$. These solutions were described herein above in detail. Overall, there was potential of $67 \%$ of waste reduction in the reference warehouse. These results demonstrate efficiency opportunities of multi-picking against single picking strategy that is less productive (Fig. 11). The comparisons of combined and not combined distances covered by the forklifts are presented in the Fig. 12.

In the summary, results of the simulation can be described by Fig. 13.

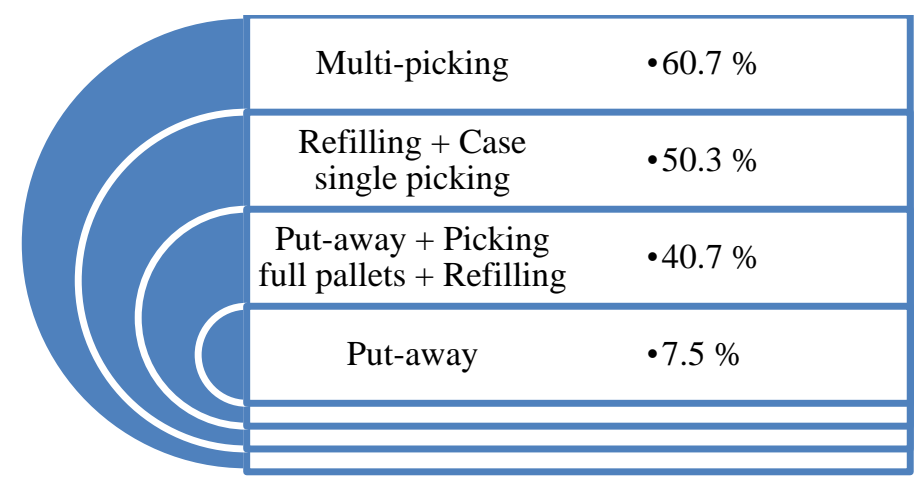

Figure 13: The summary of the simulation results.

\section{CONCLUSION}

In the literature, the topic of sustainable transportation has been receiving a lot of attention recently. There is well-documented evidence that the sustainability of inner-warehouse transportation contributes to efficiency of processes and energy savings significantly. It contributes to more efficient resource utilisation because of innovations in material handling technologies and techniques.

The contribution of this paper to the research community is a new methodology for searching activity-based improvements by employing a new concept of waste generation pyramid. An application of this concept to the case study serves as a tool aimed at identification of wasteful processes in warehouse operations. It reveals significant potential in 
avoiding waste and reaching economy of distance. In addition, the paper reveals number of opportunities to improve various inner-warehouse processes.

Based on the case study, the paper produces guidelines on how to make inner-warehouse operations more sustainable. The most of them suggest revision of assignment and schedule of warehouse's gates to suppliers; the separation of products into classes, as well as the integration of products arrival plan to warehouse; the construction of combined routes; the generation of replenishment tasks; and multi-picking implementation.

In the simulation analysis of various inner-warehouse transportation processes, the approach of integrated sustainable warehouse activities has been applied. Different strategies of integration that were employed show that location of high-volume products reception as closer as possible to their storage area gives significant total distance economy. Aiming to reach distance economy, storage locations of high volume products must be prioritized upfront as closer as possible to picking locations. It shortens total distance in the same level of significance.

Combination of various forklifts' tasks (put-away, replenishment and picking customers' pallets) for inner-warehouse operations may allow to reach total distance economy up to $40 \%$, while delivery of replenishment tasks upfront picking shortens the total distance of order pickers up to $50 \%$. Multi-picking solutions gives total distance economy even up to $60 \%$.

Further research could extend the findings of the study in the following directions:

- in search for activities generating waste in a warehouse;

- in further expansion of analysis that examines costs, size of warehouse and customers' orders;

- in application of waste pyramid in different industries.

\section{REFERENCES}

[1] Li, X.; Yeh, A. G.-O. (2001). Calibration of cellular automata by using neural networks for the simulation of complex urban systems, Environment and Planning A: Economy and Space, Vol. 33, No. 8, 1445-1462, doi:10.1068/a33210

[2] Zachariadis, T. (2005). Assessing policies towards sustainable transport in Europe: an integrated model, Energy Policy, Vol. 33, No. 12, 1509-1525, doi:10.1016/j.enpol.2004.01.008

[3] Knaak, N.; Kruse, S.; Page, B. (2006). An agent-based simulation tool for modelling sustainable logistics systems, $3^{\text {rd }}$ International Congress on Environmental Modelling and Software, Paper 161/388, 6 pages

[4] Pawlewski, P.; Greenwood, A. (Eds.), (2014). Process Simulation and Optimization in Sustainable Logistics and Manufacturing, Springer, Cham

[5] Chęciński, S. (2014). Simulation analysis of traffic congestion in mineral mining transport, Pawlewski, P.; Greenwood, A. (Eds.), Process Simulation and Optimization in Sustainable Logistics and Manufacturing, Springer, Cham, 99-109

[6] Jacyna, M.; Wasiak, M.; Lewczuk, K.; Kłodawski, M. (2014). Simulation model of transport system of Poland as a tool for developing sustainable transport, The Archives of Transport, Vol. 31, No. 3, 23-35

[7] Carteni, A. (2014). Urban sustainable mobility. Part 1: Rationality in transport planning, Transport Problems, Vol. 9, No. 4, 39-48

[8] Petranović, Z.; Vujanović, M.; Duić, N. (2015). Towards a more sustainable transport sector by numerically simulating fuel spray and pollutant formation in diesel engines, Journal of Cleaner Production, Vol. 88, 272-279, doi:10.1016/j.jclepro.2014.09.004

[9] García-Arca, J.; González-Portela Garrido, A. T.; Prado-Prado, J. C. (2017). Sustainable packaging logistics: the link between sustainability and competitiveness in supply chains, Sustainability, Vol. 9, No. 7, Paper 1098, 17 pages, doi:10.3390/su9071098 
[10] Tan, K.-S.; Ahmed, M. D.; Sundaram, D. (2010). Sustainable enterprise modelling and simulation in a warehousing context, Business Process Management Journal, Vol. 16, No. 5, 871-886, doi:10.1108/14637151011076511

[11] Lisińska-Kuśnierz, M.; Gajewska, T. (2014). Determinants of competitiveness level of refrigerated transport services companies, Polish Journal of Natural Sciences, Vol. 29, No. 4, 405-413

[12] Rosi, B.; Grasic, L.; Dukic, G.; Opetuk, T.; Lerher, T. (2016). Simulation-based performance analysis of automated single-tray vertical lift module, International Journal of Simulation Modelling, Vol. 15, No. 1, 97-108, doi:10.2507/IJSIMM15(1)8.328

[13] Wang, Y. R.; Chen, A. N. (2016). Production logistics simulation and optimization of industrial enterprise based on Flexsim, International Journal of Simulation Modelling, Vol. 15, No. 4, $732-$ 741, doi:10.2507/IJSIMM15(4)CO18

[14] Li, Z. P.; Zhang, J. L.; Zhang, H. J.; Hua, G. W. (2017). Optimal selection of movable shelves under cargo-to-person picking mode, International Journal of Simulation Modelling, Vol. 16, No. 1, 145-156, doi:10.2507/IJSIMM16(1)CO2

[15] Apak, S.; Tozan, H.; Vayvay, O. (2016). A new systematic approach for warehouse management system evaluation, Technical Gazette, Vol. 23, No. 5, 1439-1446, doi:10.17559/TV20141029094700

[16] Jerman, B.; Zrnić, N.; Jenko, M.; Lerher, T. (2017). Energy regeneration in automated high bay warehouse with stacker cranes, Technical Gazette, Vol. 24, No. 5, 1411-1416, doi:10.17559/TV$\underline{20161219112306}$

[17] Sunk, A.; Kuhlang, P.; Sihn, W. (2015). Improving productivity by deriving and defining target conditions in the value stream of packing, Transactions of FAMENA, Vol. 39, No. 3, 35-46

[18] Beker, I.; Jevtic, V.; Dobrilovic, D. (2012). Shortest-path algorithms as a tool for inner transportation optimization, International Journal of Industrial Engineering and Management, Vol. 3, No. 1, 39-45

[19] Karabegović, I.; Karabegović, E.; Mahmić, M.; Husak, E. (2015). The application of service robots for logistics in manufacturing processes, Advances in Production Engineering \& Management, Vol. 10, No. 4, 185-194, doi:10.14743/apem2015.4.201

[20] Finžgar, M.; Podržaj, P. (2017). Machine-vision-based human-oriented mobile robots: a review, Strojniski vestnik - Journal of Mechanical Engineering, Vol. 63, No. 5, 331-348, doi:10.5545/svime.2017.4324

[21] Ferbar Tratar, L. (2016). Comprehensive energy resource management for essential reduction of the total cost, Strojniski vestnik - Journal of Mechanical Engineering, Vol. 62, No. 11, 685-694, doi:10.5545/sv-jme.2016.3994

[22] Karásek, J. (2013). An overview of warehouse optimization, International Journal of Advances in Telecommunications, Electrotechnics, Signals and Systems, Vol. 2, No. 3, 111-117, doi:10.11601/ijates.v2i3.61

[23] Shukla, H.; Chhadva, J.; Arora, J.; Sheth, K.; Malhotra, K. (2017). Application of operation research in logistics and warehouse optimization, International Journal of Innovative Research in Technology \& Science, Vol. 5, No. 5, 1-7

[24] Macro, J. G.; Salmi, R. E. (2003). A simulation tool to determine warehouse efficiencies and storage allocations, Proceedings of the 2002 Winter Simulation Conference, Vol. 2, 1274-1281, doi:10.1109/WSC.2002.1166388

[25] Accorsi, R.; Manzini, R.; Maranesi, F. (2014). A decision-support system for the design and management of warehousing systems, Computers in Industry, Vol. 65, No. 1, 175-186, doi: $\underline{10.1016 / j . c o m p i n d .2013 .08 .007 ~}$ 